\title{
The study of the main soil types and their composition in the Tarnier deposit
}

\author{
Larisa Parfenova, and Olga Ekimova \\ Ural State Mining University, 620144, Ekaterinburg, Russia
}

\begin{abstract}
In this paper, soil types found on the territory of the Tarnier deposit of copper pyrite ores are considered. The contents of rock-forming components in the main soil types are determined. The analysis of excesses of permissible concentrations in soils was performed.
\end{abstract}

\section{Introduction}

This work was carried out as part of a comprehensive survey of waste disposal sites and classifying the waste as an environmental hazard class at the Tarnier deposit of copper pyrites. The work was carried out to calculate the hazard class of waste, which is determined, inter alia, taking into account the average results of samples of rock-forming soil components in the area of permanent waste disposal in accordance with clause 11 of the Order No. 536 of the Ministry of Natural Resources of Russia dated December 4, 2014 "On Approving Criteria for classifying wastes as danger class I-IV in terms of the degree of negative impact on the environment" [1].

To clarify the structural features of the soil profile in the area of the waste disposal sites, control soil sections were laid, their description was carried out, recorded in the journal, and samples were taken.

The Tarnier copper-zinc pyrite deposit is located in the Ivdel Urban District of the Sverdlovsk Region. The deposit is $32 \mathrm{~km}$ away from the administrative center of the city of Ivdel. Copper-zinc ores in the deposit are represented by massive, eutaxic veined and impregnated varieties. They are composed of pyrite, chalcopyrite, pyrrhotite and sphalerite. The host rocks are a hydrothermally altered volcanogenic complex. The ore zone comes to the surface, covered with gold-bearing formations of "iron hat" type.

Absolute elevations in the deposit area are 750-800 $\mathrm{m}$. To the east there are separate ridges and ranges with elevations of 300-600 m, against the background of water-logged valleys with elevations of less than $200 \mathrm{~m}$.

In the latitudinal-zonal plan, the studied soil region lies within the boundaries of the north-taiga subzone with spruce and spruce-fir grass-shrub forests. The forest cover of the region is above $75 \%$.

\section{Materials and methods}

The research consisted of a route survey of waste disposal sites with simultaneous sampling of soil located at the base of waste and waste storage facilities stored at the surveyed sites. 
The methodology for the soils study included field and laboratory work.

When studying soil transformation, the most informative are the signs of the morphological structure of the soil [2]. The study of soils for morphological characters, as well as sampling to determine their component composition, was carried out on a detailed topographic basis, using semi-instrumental binding of observation points.

In the field, soils were studied and determined; they were given a name according to external (morphological) characteristics. These signs characterize the processes in the soils, their occurrence and development history.

To characterize soils, study their visible signs, detect boundaries between different types of soils, and take samples for chemical analyzes, special pits called soil sections were laid [5].

The place for soils sampling was established on the basis of analysis and a detailed study of the information available before the start of field work, as well as studying the territory and the object of environmental impact (in this case, an ore deposit) directly during the route survey. All aspects that could affect the composition of the sample taken or the result of assessing the presence of contamination (exposure) were also taken into account [4].

During the selection of the location of soil sections, the following factors were taken into account:

- vertical structure, heterogeneity of the soil cover;

- terrain;

- climate;

- possibility of sampling (availability).

Based on the foregoing, for the study area of the Tarnier deposit, the following features were identified that influenced the location of the sampling points:

1. The soil cover at the research site is thin, represented everywhere by brown podzolized soils. Other varieties of soil are absent. Horizon A (humus) is weakly expressed, or is determined only as a part of the undivided horizon $A B$ (humus-illuvial). It can be noted that due to the presence of only one soil variety, this factor practically did not affect the choice of the point location. Based on soil characteristics, a combined sample was selected from each section, containing soil from horizons A and B.

2. According to the relief location, the survey sites are located on the slopes. The sampling points were confined to the same relief elements.

3. According to the climatic characteristics, winds of north and west directions prevail in the region. According to the requirements of regulatory documents, sampling points were placed along the vectors of the "wind rose", i.e. mainly on the east and south sides of waste disposal facilities along the path of pollution.

4. The research area is a terrain disturbed during opencast mining, characterized by a large difference in elevations. In such conditions, one of the factors affecting the choice of the location of the sampling point is the availability of an way or access to it, as well as the ability to take a soil sample at the point.

Soil sampling was carried out in accordance with GOST 17.4.3.01-83, GOST 17.4.4.02$84[5,6]$.

During the testing, sampling reports were drawn up, in which the following points were recorded: number of observation points, their location, weather conditions, depth of sampling, name of the source of harmful effects and distance from it, soil type, sample number, soil sample weight, date of sampling, data on the specialists who performed sampling. In the sampling report it is also necessary to note the characteristic features of the landscape of the territory, its slope.

Sample preparation and determination of the chemical composition of soils were carried out by specialists of the Federal State Institution "TsLATI in UFD (Center for Laboratory 
Analysis and Technical Measurements in the Ural Federal District)" according to the following regulatory documents: GOST 17.4.4.02-84 [5].

\section{Results and discussion}

Performed sections in general can be represented as follows:
$\mathrm{A}_{0}{ }^{\prime} \quad 0-1 \mathrm{~cm}$
$\mathrm{A}_{0} " \quad 1-4(6) \mathrm{cm}$
Heavy coniferous leaf litter
$\mathrm{A}_{1} \mathrm{~A}_{2} \quad 4-15 \mathrm{~cm}$
Litter of medium degree of decomposition, brown, divided into leaf, soil en and humus layer, bound by roots, loose, fresh

$\begin{array}{ll}\mathrm{B}_{1} \mathrm{~m} & 15-25 \mathrm{~cm} \\ \mathrm{~B}_{2} \mathrm{~m} & 25-48 \mathrm{~cm}\end{array}$
Grayish-brown color. Dusty-finely lumpy structure. Represented by mec Woody, wet. There are weakly decomposed residues and roots of plants. C transition
Brown color. Unclear, lumpy structure. Represented by heavy loam. Con1 roots and plant debris, small inclusions of black color are found. Wet. Gradual Grayish-brown color. Slabby, coarse blocky structure. Represented by $h_{1}$ Separately, small plant roots, diffuse ocherous contractions, and a small amou rock are found. Wavy, clear in color transition.
$\mathrm{BC} \quad 48-68 \mathrm{~cm}$ Brown in color with greenish-gray edges. Soil separates structure is uncle; nutty. Represented by heavy loam. Heavily woody, wet

$\mathrm{BC} \quad 48-68 \mathrm{~cm}$

It should be noted that despite the fact that all studied soil sections have common horizontal features and belong to the same type of soil, they all have their own characteristic features.

As a result of studies on determination of the types of soils based on morphological analysis of sections and the appearance of soils and data from past studies, it was established that the studied soils of the Tarnier deposit are brown podzolized (figure) [7, 8]. Other varieties of soil are absent.

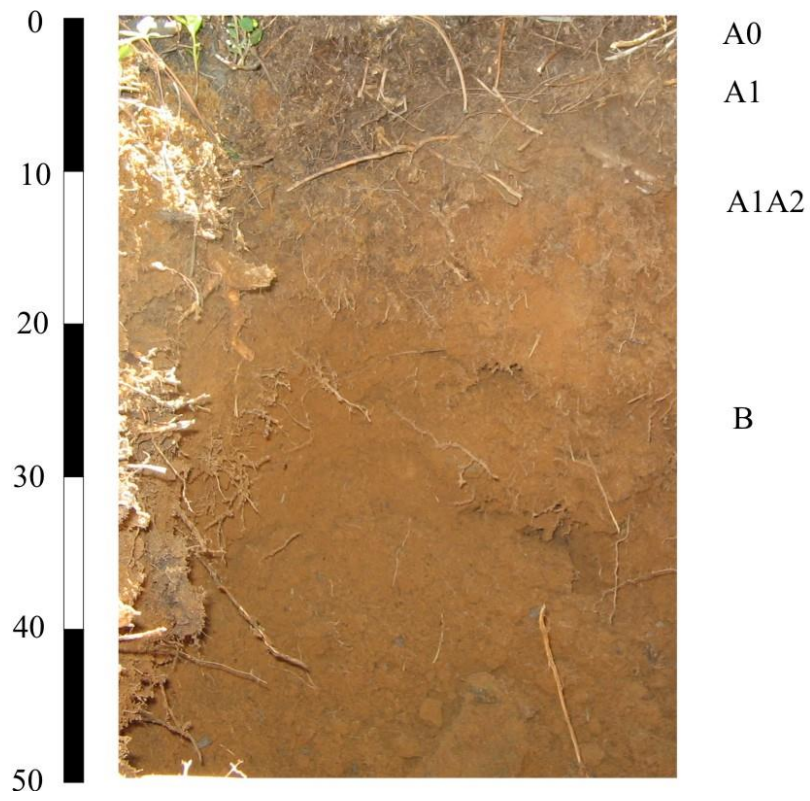

Fig. 1. Brown forest soils in the Tarnier deposit area.

The studied soils are characterized by clay-loamy-sandy loam mechanical composition, acidic reaction of the medium.

Initial (background) characteristics can serve as criteria for the ecological state of soils. 
Based on the materials studied in the area of work, 16 chemical elements were identified, the presence of which is most characteristic for the soils of this area. These are the so-called typomorphic elements. At their high concentrations, they can be dangerous for the area ecosystems. These elements included: aluminum, vanadium, iron, cadmium, calcium, silicon dioxide, magnesium, manganese, copper, arsenic, nickel, lead, copper, chromium and zinc $[5,7]$.

Aluminum. One of the most common components of the earth's crust, it is present in rocks in an amount of $0.45-10 \%$ (Clarke $8.07 \%$ ). The total aluminum content in soils depends on the parent rock. In acidic soils $(\mathrm{pH}<5.5)$, aluminum activity increases, and upon ion exchange it actively competes with other cations. Mobile aluminum in acidic soils is quickly absorbed by plants, which can cause them chemical stress.

Vanadium. The behavior of vanadium in soils has been little studied. In the soil section, it is distributed fairly evenly; concentration fluctuations are associated with the composition of the parent rock. Clay-loamy and sandy soils contain an increased amount of vanadium, exceeding its concentration in parent rocks. The increased content of vanadium in soils is associated with iron oxides. In this form, it is most mobile and therefore available for plants. Vanadium clarke $9 \cdot 10-3 \%[5,7]$.

Iron. Iron is one of the main elements in the earth's crust. Iron content is about $5 \%$ of its mass. Iron is accumulated mainly in igneous rocks of the main composition. In soils, the element is found in the form of oxides and hydroxides. The content varies from 0.5 to $5 \%$, depending on the composition of the parent rocks. Soils having a $\mathrm{pH}<5.5$ contain the highest concentrations of inorganic iron. Clarke content is $4,65 \%[5,7]$.

Cadmium. Cadmium clarke - $1,3 \cdot 10-3 \%$. In the biosphere it is scattered, living matter does not accumulate it, it is toxic. Cadmium enters the soil as a result of adsorption on organic compounds and iron and manganese oxides. It has the highest migration ability in acidic soils (at $\mathrm{pH} 4.5-5.5$ ); with increasing $\mathrm{pH}$, the mobility of cadmium decreases.

Calcium. It is in fifth place in terms of its content in the earth's crust, its clarke is 2.96 . $10-3 \%$. Calcium is the main metal of living matter. It is easily leached from soil as a result of erosion. Content in soils varies over a wide range, depending on the chemical and mechanical composition of soils and parent rocks.

Silicon dioxide. This is the second most common element of the earth's crust, with a clarke of $29.5 \%$. In geochemistry, its compound is mainly considered - silica (SiO2). It is accumulated in acidic igneous rocks. In landscapes, silicon migrates rapidly in the humid tropics, tundra and taiga, and it is weaker in the steppes and deserts [7].

Magnesium. According to A.P. Vinogradov, magnesium clarke is equal to $1.87 \%$. In humid landscapes, magnesium moves similarly to calcium, but it is less mobile. In migration in arid landscapes, it is similar to sodium and aluminum, so there is more of it.

Manganese. This metal is quite often found in soils. In the steppe and desert zones, it is inactive, therefore its content is low in chernozems. In acidic and neutral waters of humid landscapes it migrates well, often forming nodules in soils. Clarke - $0.1 \%$.

Copper. A relatively weakly migrating element in soils, since it forms poorly soluble compounds such as sulfides and hydroxides. Highly toxic. The total copper content has relatively weak variations in the soil section. Average copper concentrations in soils vary from 6 to $60 \mathrm{mg} / \mathrm{kg}$. The maximum contents are noted in laterite soils, the minimum - in sandy soils and in soils with a large amount of organic matter. Clarke is $4,7 \cdot 10-3 \%$.

Arsenic. Clarke is $1,7 \cdot 10-4 \%$. An important biological element, but with significant excess of clarke concentrations is highly toxic. In the soils of the steppes and deserts, arsenic is inactive. In a humid climate, it is actively washed out from the soil.

Nickel. Nickel. The concentration of nickel in soils, taking into account clarke, is 85 $\mathrm{mg} / \mathrm{kg}$. 
Lead. Clarke is $1,6 \cdot 10-3 \%$. In the biosphere it is mainly dispersed. In humid landscapes, it migrates in bicarbonate form, in organic complexes and mechanically with clay particles. In the soils of the steppes and deserts, it is inactive. Highly toxic. The ratios of the various migratory forms of lead showed that they depend on the soil horizon and type. The greatest mobility of lead is characteristic for acidic sod-podzolic soils.

Sulphur. It has a relatively high clarke $4,7 \cdot 10-2 \%$. Alkali sulfates are highly soluble, while calcium and lead are poorly soluble. Sulphides of heavy metals are also poorly soluble. Sulfur is concentrated in the biosphere and sedimentary rocks.

Chrome. Inactive in humid landscapes, eluvial soils of steppes and deserts. In a sharply oxidizing alkaline environment, oxidation to $\mathrm{Cr} 3+\mathrm{Cr} 6+$ is possible, which in some places is accumulated during salinization. Highly toxic. Clarke in the earth's crust is $8.3 \cdot 10-3 \%$. $[5,7]$.

Zinc. Zinc clarke is $8.3 \cdot 10-3 \%$. It is an important biological element. It is also often found in soils and is easily mobile, especially in acidic soils. It is found in maximum concentrations in the humus and illuvial horizons of soils. Solubility is limited by the presence of calcium and phosphorus compounds in soils. Soluble forms of zinc are absorbed by biota $[5,7]$.

The considered criteria can be used to assess the ecological state of soils.

According to the results of quantitative chemical analysis, silicon dioxide (over $70 \%$ by weight), aluminum, iron, sulfur, and magnesium are predominate in the component composition of soils (table).

Table 1. The content of elements in the soils of the Tarnier deposit.

\begin{tabular}{|c|c|c|c|}
\hline Defined characteristic & $\begin{array}{l}\text { Content, } \mathrm{mg} / \mathrm{kg} \\
\underline{\text { min-max }} \\
\text { average }\end{array}$ & $\begin{array}{l}\mathrm{APC}, \\
\mathrm{mg} / \mathrm{kg} \\
{[10]}\end{array}$ & $\begin{array}{l}\text { Clarke according } \\
\text { to Vinogradov, } \\
\mathrm{mg} / \mathrm{kg} \mathrm{[7]}\end{array}$ \\
\hline Aluminium $(\mathrm{Al})$ & $\frac{34169-41531}{39577}$ & - & 80500 \\
\hline Vanadium (V) & $\frac{73.2-162.0}{121.0}$ & - & 90 \\
\hline Iron $(\mathrm{Fe})$ & $\frac{33612-38341}{36353}$ & - & 46500 \\
\hline Cadmium $(\mathrm{Cd})$ & $<0.05$ & 1.0 & 0.13 \\
\hline Calcium $(\mathrm{Ca})$ & $\frac{2691-10153}{5473}$ & - & 29600 \\
\hline Silicon dioxide $\left(\mathrm{SiO}_{2}\right), \%$ & $\begin{array}{l}70.9-75.4 \\
73.0\end{array}$ & - & 29.5 \\
\hline Magnesium (Mg) & $\frac{6746-7830}{7398}$ & - & 18700 \\
\hline Manganese (Mn) & $\frac{241-524}{418}$ & - & 850 \\
\hline Copper $(\mathrm{Cu})$ & $\frac{93.8-202.0}{149.0}$ & 66 & 47 \\
\hline Arsenic (As) & $<0.1$ & 5 & 1.7 \\
\hline Nickel (Ni) & $\frac{13.8-16.3}{15.0}$ & 40 & 40 \\
\hline Lead $(\mathrm{Pb})$ & $\frac{0-340.0}{113.3}$ & 65 & 16 \\
\hline Sulphur (S) & $\frac{687-2541}{1348}$ & - & 470 \\
\hline Chrome & $\frac{6.7-22.2}{17.0}$ & - & 83 \\
\hline Zinc $(\mathrm{Zn})$ & $\frac{129-177}{155}$ & 110 & 83 \\
\hline Hydrogen index $(\mathrm{pH}), \mathrm{pH}$ units & $\frac{5.14-5.40}{5.30}$ & - & \\
\hline
\end{tabular}


As can be seen from the table at the Tarnier deposit there is an excess in the soils of approximate permissible concentrations (APC) of copper (1.4-3 APC), lead (5.2 APC, one sample), zinc (1.2-1.6 APC)

Clarke concentrations in soils are exceeded for vanadium (up to 1.6 clarke), silicon dioxide (2.6 clarke), copper (2-4.3 clarke concentrations), sulfur (5.4 clarke), zinc (1.6- 2.1 clarke), lead (21.3 clarke, one sample).

\section{Conclusions}

Thus, according to the results of the studies, it can be noted that the excess of permissible and background concentrations of heavy metals in soils is characteristic, mainly, only for copper and zinc, also contained in the ores of the deposit. Similar contents in soils indicate that soils are formed on the parent rock with a high content of these components. I.e. there is an increased natural background of the concentrations of these metals in the soil.

According to the results of quantitative chemical analysis of waste samples, a hazard class was calculated taking into account the content of rock-forming components in the soil. Waste is assigned to 5 hazard class.

\section{References}

1. «On approval Of criteria for classifying waste to hazard classes I-V according to the degree of negative impact on the environment» Order Of The Ministry of natural resources of Russia №536 04.12.2014.

2. J. E. Saet, E. P. Revich, E. P. Yanin, Geochemistry of the environment, (1990)

3. V. V. Ivanov, Ecological geochemistry of elements, 4, (1997)

4. A. Kabata-Pendias, H. Pendias, Trace elements in soils and plants, (1989)

5. GOST 17.4.3.01-83. Nature protection. Soils. General requirements for sampling (1983)

6. GOST 17.4.4.02-84. Nature protection. Soils. Methods of sampling and preparation of samples for chemical, bacteriological, helminthological analysis (1984)

7. A. I. Perelman, Geochemistry, (1989)

8. M. A. Glazovskaya, Problems and methods of assessment of ecological and geochemical stability of soils and soil cover to technogenic impacts, (1999)

9. A. I. Semyachkov, Metals in the environment of mining and metallurgical complexes of the Urals, (2001)

10. GN 2.1.7.2511-09. Approximate permissible concentrations (ODC) of chemicals in soil (2009) 